\title{
Death Announcement: Difficulties and Pediatricians' Experiences
}

\author{
Mariam Lagrine*, Fatiha Bennaoui, Nadia El Idrissi Slitine, Fadl Mrabih Rabou Maoulainine \\ Department of Pediatric, Neonatal Intensive Care Unit, Mohammed VI University Hospital, Marrakesh, Morocco \\ Email address: \\ Lagrine.mariam@gmail.com (M. Lagrine) \\ ${ }^{*}$ Corresponding author \\ To cite this article: \\ Mariam Lagrine, Fatiha Bennaoui, Nadia El Idrissi Slitine, Fadl Mrabih Rabou Maoulainine. Death Announcement: Difficulties and \\ Pediatricians' Experiences. International Journal of Psychological and Brain Sciences. Vol. 5, No. 2, 2020, pp. 28-30. \\ doi: 10.11648/j.ijpbs.20200502.11
}

Received: May 1, 2020; Accepted: June 10, 2020; Published: June 20, 2020

\begin{abstract}
Notification of death is a shock for the family but also for the caregiver. However, there is a tendency to forget the feelings of caregivers about this theme. The objective of our study is to evaluate doctors feelings and the difficulties during the announcement of deaths. Methods: A qualitative, exploratory study involving 34 doctors exercising at the pediatric center of the Mohammed VI university hospital in Marrakesh. To explore doctors' experiences in providing care, their emotional reactions to the patient's death, and their use of coping and social resources to manage their emotions. Results: An amount of doctors reported death between 5 to 10 times in $35.3 \%$ and between 10 to 20 times in $26.4 \% ; 41.2 \%$ of the cases reported a feeling of sadness during the notification, $29.4 \%$ felt dizzy and $29.4 \%$ revealed a stress. Twenty-one doctors had felt the need of support and a psychologist consultation to talk and express themselves. A percentage of $97 \%$ of physicians said they had never received any training on the death notification and felt that training in this sense was useful and necessary. Conclusion: notification of death remains a difficult test, it requires preparation as well as learning by training especially when it comes to announcing the death of a child.
\end{abstract}

Keywords: Pediatrician, Death, Communication, Pain, Children

\section{Introduction}

Announcing death is an important and delicate medical procedure, whose emotional impact on the patient can be considerable. This is a stressful time for doctors and parents.

Previous research has linked level of training with doctors emotional reactions to deaths. In a longitudinal study "dealing with death and dying" was the most commonly reported source of stress of many doctors, and it was related to psychological distress [1].

As for the announcement of bad news, it is "an eternal minute", "It is the subject of a kind of taboo". However, patient information is a human right and a responsibility of the healthcare professional [2].

It is important to try to minimize any discomfort felt by one or other of the interlocutors. According to Robert BUCKMAN, a medical interview generally takes place in two stages. One is for announcing information to the patient, the other is to dialogue with the patient. The latter begins more or less quickly depending on the reactions of the person concerned. It consists of listening, answering any questions, and giving information on short-term care. The time spent on this interview varies depending on the healthcare professional and the patient [3].

Doctors as a health professional have to deal with illness, suffering and death. They must announce the death of a loved one, a child to their family, which breaks the meaning of their life. Many of these stories reflect the sadness, guilt, and stress caused by announcing death or caring for dying patients. Such stress has been linked to professional burnout and may put doctors at risk of psychiatric disorder.

In Moroccan society, what is the feeling of pediatricians while announcing death and what difficulties do they encounter?

\section{Materials and Methods}

The study took place at the Mohamed VI University Hospital Center in Marrakech, with 34 doctors (including interns and residents) practicing at the pediatric center, during 
the month of April 2018.

The information was collected through an anonymous questionnaire containing information about the doctors with multiple questions assessing the announcement of the death and the difficulties encountered, to explore doctors' experiences in providing care and their emotional reactions to the patient's death.

\section{Results}

The doctors interviewed had different levels of experience. The most dominant age group varied between 20 to 30 years in $73.5 \%$. On average, doctors had announced death between 5 to 10 times in $35.3 \%$ during their exercise at the Center Hospitalier University Mohamed VI in Marrakesh.

At the time the doctors diagnosed the death, their emotions immediately after the announcement were as follows:

8 pediatricians report a feeling of sadness, 7 report unhappiness and 5 others reported a feeling of fear, to "use the wrong words" or "fear of the first reactions".

Other types of feelings have been regularly reported such as failure, emotional shock, stress, misunderstanding. Twenty-five doctors had defined "announcement of death" as: a drama for the parents but also for them, six spoke of shock and three others: felt guilt, especially Doctors who spend a longer time caring for their patients get to know them better but this also makes them more vulnerable to feelings of loss when these patients die.

Death is usually brutal, sudden or unforeseen in the sense that the family is not prepared for it. It readily results from violence, trauma, suicide or assault, and often affects the doctor. In our study, six cases were victims of assault at the time of death, either by parents or other family members. Among the doctors interviewed, twenty-one felt the need for support and consultation with a psychologist to talk about it and express themselves.

$97 \%$ of doctors said that they had never received training on the notification of death and considered that training in this sense was useful and necessary for helping doctors in training to construct their losses in a meaningful and adaptive manner.

\section{Discussion}

Announcing the death of a patient to his family is one of the responsibilities of health professionals. This is a delicate moment that will start mourning and that each doctor approaches differently. This announcement is a shock for the family but also for physicians [4].

This announcement of death or of bad news is one of the most daunting tasks faced by physicians. For many, their first experience involves patients they have known only a few hours. Additionally, they are called upon to deliver the news with little planning or training [1].

Usually, medicals studies have concentrated on technical proficiency than communication skills. This leaves physicians unprepared for the communication complexity and emotional intensity of breaking bad news [5]. The frightened doctors have about delivering bad news include being blamed, evoking a reaction, expressing emotion, not knowing all the answers, fear of the unknown and untaught, and personal fear of illness and death $[1,6]$.

However, all caregivers recognize that the issue is important and that they play an essential role in the grieving process. It is up to the medical team to find the right words, the answers adapted to each case to allow families to feel supported, supported and listened to.

In lot off publications and studies do it about experiences of doctors during the announcement of death for example Ellen M Redinbaugh and all [1] found that doctors reported "feeling upset when thinking about the patient" more than any other grief symptom, and "getting emotional support from others" was their primary coping strategy. Contrary to our expectations, junior doctors did not differ from attending physicians in their emotional reactions to patients' deaths.

The announcement of bad news gives negative emotions among doctors, the effects of which can be reduced in the context of training using methods such as consultation simulations and discussion groups.

Doctors have many difficulties when they are communicating with patients, with patients' relatives, and with professional colleagues.

Their experience alone can't help them to resolve these problems, but the necessity of training on communication skills can help to face those difficulties by Participating in a course had a significant beneficial effect on both the attitudes and communication styles $[7,8]$.

For that Robert BUCKMAN describes six steps necessary to announce bad news [9], based on the big role of effective communication between doctors and patients or family patients. The communication has beneficial effects; it's an important determining the accuracy and of the data collecting on symptoms and side effects, dictates problems caused, emotional and physical influence well-being and contributes to the satisfaction of both clinician and patients [10].

1. "Preliminaries": The goal, for the caregiver, is to create an intimate atmosphere, to take into account the patient's condition and to show that he is in control of the situation.

2. The second phase consists in trying to find out what the patient has already understood, knowing that he can sometimes deny the events. It makes it possible to assess the emotional state in which he is as well as his level of education, in order to adapt the language.

3. The third phase: the caregiver must try to find out what the patient wants to know or not. However, in some cases, such as the announcement of a death, he will inevitably be confronted with reality.

4. The fourth phase: the information is transmitted to the patient. The language must be adapted to its level of comprehension. The healthcare professional will announce the diagnosis and begin to discuss treatment, prognosis, and support in more or less detail. Often the patient remembers only part of what was said to them.

5. The fifth phase corresponds to the reception of the 
patient's feelings.

6. The sixth is to offer follow-up.

Death is often experienced as a personal failure of the physicians and medical stuff. The impossibility for some to accept the death of the patient leads to avoidance behavior or relentless therapy [11].

Be aware that the announcement of death can trigger stress, guilt, denial, anger, resignation and

sadness for the physicians. It can also result in psychological trauma, distress, doubt, a feeling of helplessness.

There is no way to announce a death that is not painful for families, but it is possible to implement a fairly stereotypical approach that avoids increasing the emotional trauma of everyone, including the doctor [6]. Not everyone has the benevolent and empathetic detachment to always be able to assume, whatever the circumstances, the announcement to the loved ones of a death.

Authors emphasize the importance of training doctors to know and manage their own defense mechanisms, given their influence on their practice and experience: projective identification, rationalization, trivialization, avoidance, false reassurance, derision, lies, headlong, etc.

The skills to be acquired are: theoretical (knowledge of defense mechanisms), practical (communication and listening) [8] and human (reflections and sharing on death, suffering, their profession).

\section{Conclusion}

Whatever the explosion of scientific discoveries and the rational organization of knowledge to reveal a diagnosis, prognosis and treatment, these scientific discoveries for diseases must be harnessed to the patient and doctor as parts of the doctor-patient relationship. This relationship requires an effective means reciprocal communication and consistent not any denying the subjective dimension of the two subjects present in their cognitive and emotional perception of physiological problems, especially in chronic disease, cancer or announcing bad news. The acquisition of an effective communication skills has always been the object of empirical studies, they concord that doctors could improve communication skills by communication training programs.

\section{Declaration of Conflict of Interest}

The authors declare that they have no conflict of interest.

\section{References}

[1] Redinbaugh, E. M., et al., Doctors' emotional reactions to recent death of a patient: cross sectional study of hospital doctors. Bmj, 2003. 327 (7408): p. 185.

[2] Krakowski, A. J., Stress and the practice of medicine II. Stressors, stresses, and strains. Psychotherapy and psychosomatics, 1982. 38 (1-4): p. 11-23.

[3] Clément-Hryniewicz, N., Facing impending death and physical and/or psychic degradation: suffering of patients and their families. Thinking about the suffering endured by patients with cancer and their families in palliative care. L'Information Psychiatrique, 2012. 88 (9): p. 735-741.

[4] Ptacek, J., et al., Breaking bad news to patients: physicians' perceptions of the process. Supportive Care in Cancer, 1999. 7 (3): p. 113-120.

[5] Lutfey, K. and D. W. Maynard, Bad news in oncology: How physician and patient talk about death and dying without using those words. Social Psychology Quarterly, 1998: p. 321-341.

[6] Purdy, R., et al., Resident physicians in family practice: who's burned out and who knows? Family medicine, 1987. 19 (3): p. 203-208.

[7] Jenkins, V. and L. Fallowfield, Can communication skills training alter physicians' beliefs and behavior in clinics? Journal of Clinical Oncology, 2002. 20 (3): p. 765-769.

[8] Libert, Y. and C. Reynaert, Les enjeux de la communication médecin-patient et l'importance des caractéristiques psychologiques du médecin. Psycho-oncologie, 2009. 3 (3): p. 140-146.

[9] Buckman, R., Breaking bad news: why is it still so difficult? British medical journal (Clinical research ed.), 1984. 288 (6430): p. 1597.

[10] Fallowfield, L., et al., Efficacy of a Cancer Research UK communication skills training model for oncologists: a randomised controlled trial. The Lancet, 2002. 359 (9307): p. 650-656.

[11] Dauchy, S. and N. Bendrihen, Annonce et vécu psychologique, in Thérapeutique du cancer. 2011, Springer. p. 945-956. 